\title{
A longitudinal study of fecal calprotectin and the development of inflammatory bowel disease in ankylosing spondylitis
}

Eva Klingberg ${ }^{1 *}$, Hans Strid ${ }^{2,3}$, Arne Ståhl ${ }^{4}$, Anna Deminger ${ }^{1}$, Hans Carlsten ${ }^{1}$, Lena Öhman ${ }^{4,5}$ and Helena Forsblad-d'Elia ${ }^{1,6}$

\begin{abstract}
Background: Patients with ankylosing spondylitis (AS) are at increased risk of developing inflammatory bowel disease (IBD). We aimed to determine the variation in fecal calprotectin in AS over 5 years in relation to disease activity and medication and also to study the incidence of and predictors for development of IBD.

Methods: Fecal calprotectin was assessed at baseline $(n=204)$ and at 5-year follow-up $(n=164)$. The patients answered questionnaires and underwent clinical evaluations. At baseline and at 5-year follow-up, ileocolonoscopy was performed in patients with fecal calprotectin $\geq 500 \mathrm{mg} / \mathrm{kg}$ and $\geq 200 \mathrm{mg} / \mathrm{kg}$, respectively. The medical records were checked for diagnoses of IBD during the follow-up period.

Results: Fecal calprotectin $>50 \mathrm{mg} / \mathrm{kg}$ was found in two-thirds of the patients at both study visits. In $80 \%$ of the patients, fecal calprotectin changed by $<200 \mathrm{mg} / \mathrm{kg}$ between the two measuring points. Baseline fecal calprotectin was positively correlated with Ankylosing Spondylitis Disease Activity Score based on C-reactive protein, Bath Ankylosing Spondylitis Disease Activity Index, Bath Ankylosing Spondylitis Functional Index, C-reactive protein, erythrocyte sedimentation rate, and fecal calprotectin at 5-year follow-up. The use of nonsteroidal anti-inflammatory drugs (NSAIDs) was associated with higher fecal calprotectin, and 3-week cessation of NSAIDs resulted in a drop of a median $116 \mathrm{mg} / \mathrm{kg}$ in fecal calprotectin. The use of tumor necrosis factor (TNF) blockers was associated with lower fecal calprotectin at both visits, but the users of TNF receptor fusion proteins had significantly higher fecal calprotectin than users of anti-TNF antibodies at 5-year follow-up. The 5-year incidence of Crohn's disease (CD) was $1.5 \%$ and was predicted by high fecal calprotectin.
\end{abstract}

Conclusions: Fecal calprotectin was elevated in a majority of the patients and was associated with disease activity and medication at both visits. CD developed in $1.5 \%$ of the patients with AS, and a high fecal calprotectin was the main predictor thereof. The results support a link between inflammation in the gut and the musculoskeletal system in AS. We propose that fecal calprotectin may be a potential biomarker to identify patients with AS at risk of developing IBD.

Trial registration: ClinicalTrials.gov identifier: NCT00858819. Registered 9 March 2009. Last updated 28 May 2015.

Keywords: Ankylosing spondylitis, Spondylarthritis, Inflammatory bowel disease, Fecal calprotectin, Crohn's disease, Ulcerative colitis, Intestinal inflammation

\footnotetext{
* Correspondence: eva.klingberg@vgregion.se

'Department of Rheumatology and Inflammation Research, Sahlgrenska

Academy at the University of Gothenburg, Guldhedsgatan 10A, S-413 46

Gothenburg, Sweden

Full list of author information is available at the end of the article
} 


\section{Background}

Ankylosing spondylitis (AS), Crohn's disease (CD), and ulcerative colitis (UC) are inflammatory diseases that have many common features. Several risk genes are shared between the spondylarthritides and inflammatory bowel disease (IBD), and the diseases can show coinheritance [1-4]. Patients with IBD can develop peripheral arthritis (10-20\%), sacroiliitis (10-20\%), and anterior uveitis (0.5$3 \%)$ [5-9]. Studies have revealed the presence of endoscopic and histologic gut inflammation in $40-60 \%$ of patients with AS and in $46 \%$ of patients with early spondylarthritis (SpA) [10-13]. The subclinical gut inflammation in AS is often localized to the colon or the distal ileum. Histologically, the inflammation has been divided into an acute form and a chronic form, the latter resembling $\mathrm{CD}$ and conferring an increased risk for subsequent development of IBD [14-16]. Approximately 5-10\% of patients with SpA eventually develop IBD, with CD being more common than UC $[17,18]$. There is a lack of knowledge about what predicts the development of IBD in AS, however, and clinical studies on the subject are rare [19].

Fecal calprotectin is an unspecific marker for gut inflammation. Calprotectin belongs to the family of calciumbinding calgranulins (or S100 proteins) and consists of heterodimers of the two proteins S100A8 and S100A9. Calprotectin is an abundant protein in the neutrophils, constituting up to $40-60 \%$ of the cytosolic protein content, and it is also found in gut epithelial cells, monocytes, and macrophages. The level of calprotectin in feces is proportional to the level of neutrophil inflammation in the gut [20]. Fecal calprotectin is clinically used to discriminate IBD from irritable bowel syndrome and correlates well with clinical, endoscopic, and histologic measures of disease activity in IBD $[21,22]$. Fecal calprotectin is also increased in enteropathy caused by nonsteroidal anti-inflammatory drugs (NSAIDs) [23].

We have previously investigated the levels of fecal calprotectin in a cohort of 204 patients with AS. We found that $68 \%$ of the patients had elevated levels $(>50 \mathrm{mg} / \mathrm{kg})$ and that fecal calprotectin was associated with higher disease activity but not with gastrointestinal symptoms [24]. The same patients were then invited to be reexamined at a 5-year follow-up examination.

The aims of this 5-year prospective study on AS were (1) to investigate the intraindividual variations in fecal calprotectin over time in relation to disease activity, disease manifestations, and medication; (2) to study the 5year incidence of IBD; and (3) to identify predictors for the development of IBD.

\section{Methods}

\section{Patients}

All patients fulfilling the modified New York criteria for AS who were registered at the rheumatology clinics at
Sahlgrenska University Hospital and the hospitals of Borås and Alingsås were invited to participate in the study in 2009, hereafter called baseline [24, 25]. Exclusion criteria were diagnosed IBD, psoriasis, dementia, pregnancy, and difficulties in understanding the Swedish language. Altogether, 204 patients were included at baseline and 164 (80\%) patients were reexamined at the 5-year follow-up in 2014. All patients gave their written informed consent. The study was approved by the regional ethics committee in Gothenburg and was carried out in accordance with the Helsinki declaration. A flowchart of the enrollment of the patients and the study procedures is shown in Fig. 1. The patients underwent the same assessments at both visits, including physical examinations and responding to questionnaires. Blood and stool samples were collected. The medical records of all the included patients at baseline were checked for ileocolonoscopies, episodes of gut inflammation, or diagnoses of IBD.

\section{Questionnaires}

The Ankylosing Spondylitis Disease Activity Score based on C-reactive protein $\left(\mathrm{ASDAS}_{\mathrm{CRP}}\right)$, Bath Ankylosing Spondylitis Disease Activity Index (BASDAI), Bath Ankylosing Spondylitis Patient Global Score, and Bath Ankylosing Spondylitis Functional Index (BASFI) were used to assess disease activity and physical function. Back mobility was measured for the calculation of Bath Ankylosing Spondylitis Metrology Index (BASMI) [26].

\section{Stool samples}

Stool samples were collected by the patients and sent to the laboratory, where the samples were immediately frozen. After thawing of the samples, fecal calprotectin was analyzed using an enzyme-linked immunosorbent assay (ELISA) kit (Bühlmann Laboratories AG, Schönenbuch, Switzerland). The same ELISA kit and procedures were used at baseline and at 5-year follow-up. In the general population, fecal calprotectin is $<50 \mathrm{mg} / \mathrm{kg}$, according to the manufacturer of the kit.

\section{Blood samples}

Blood samples were analyzed for hemoglobin, erythrocyte sedimentation rate (ESR), and C-reactive protein (CRP) using standard laboratory techniques. Serum calprotectin was analyzed at baseline by ELISA (PhiCal; Immundiagnostik AG, Bensheim, Germany) following the manufacturer's instructions. According to the manufacturer, the normal range for serum calprotectin is $500-3000 \mathrm{ng} / \mathrm{ml}$.

\section{Ileocolonoscopy}

At baseline, all patients with fecal calprotectin $\geq 500 \mathrm{mg} / \mathrm{kg}$ were asked to send in a new stool sample. NSAID use was not stopped. If their fecal calprotectin remained $\geq 500 \mathrm{mg} /$ $\mathrm{kg}$, the patients were advised to undergo a clinical routine 


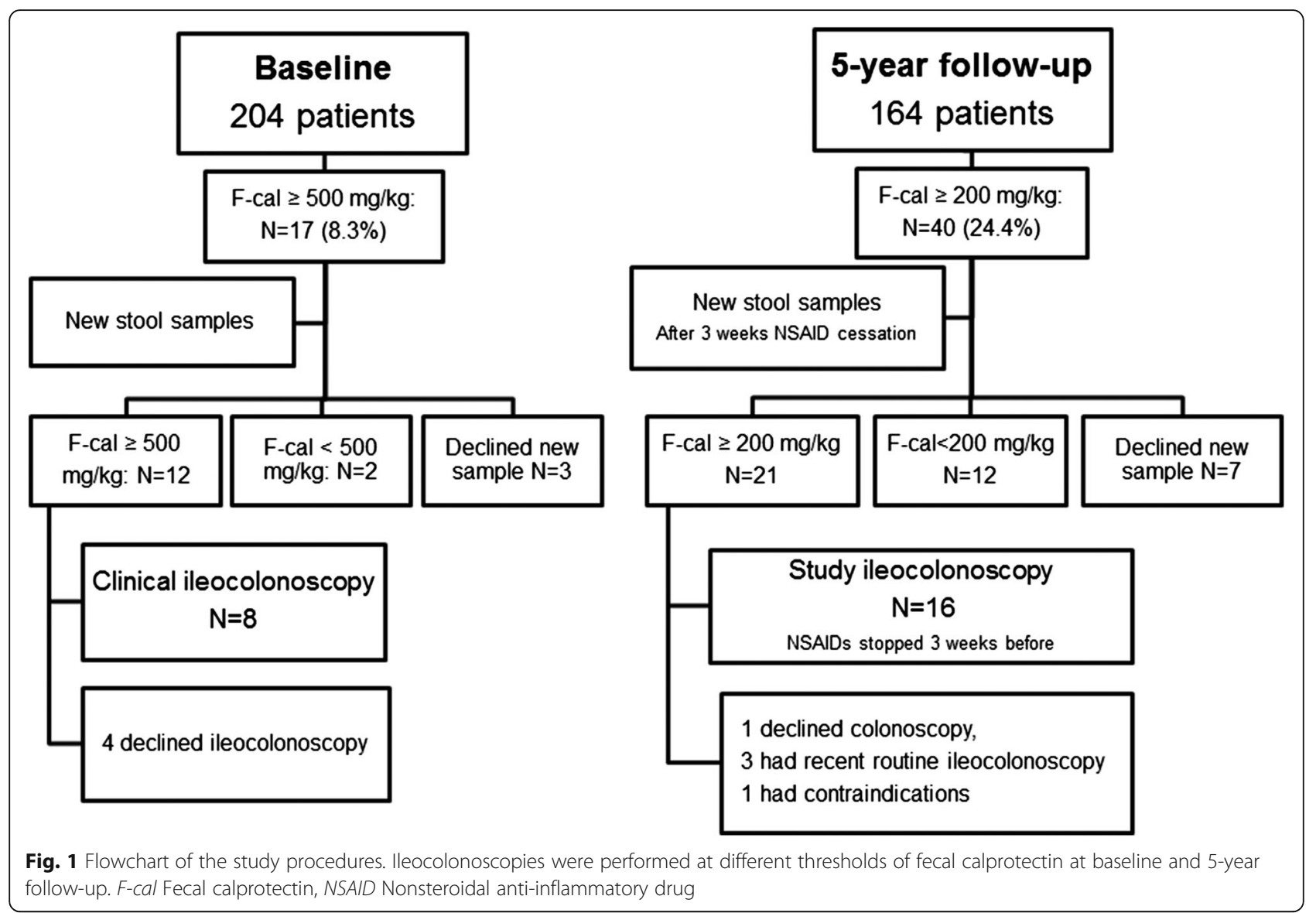

ileocolonoscopy (Fig. 1). At 5-year follow-up, all patients with fecal calprotectin $\geq 200 \mathrm{mg} / \mathrm{kg}$ were asked to send in another stool sample after pausing NSAID medication for 3 weeks. If their fecal calprotectin remained $>200 \mathrm{mg} / \mathrm{kg}$ when retested, the patients were referred for ileocolonoscopy. Before the ileocolonoscopy, NSAIDs were again paused for 3 weeks. At 5-year follow-up, all ileocolonoscopies were performed by one endoscopist (HS) and followed the same procedure.

\section{Data analyses}

Data from all patients who participated at baseline $(n=$ 204) were analyzed with the aim of determining the 5-year incidence of IBD and the predictors thereof. For all other data analyses, only the patients who participated both at baseline and at 5 -year follow-up $(n=164)$ were included.

\section{Statistical analyses}

Statistical analyses were performed using IBM SPSS Statistics 23 software (IBM, Armonk, NY, USA). Descriptive statistics are presented as median and IQR. In comparisons between groups, the Mann-Whitney $U$ test was used for continuous variables, and the chi-square test or Fisher's exact test was used for categorical variables. The Wilcoxon signed-rank test was used for repeated measurements.
Correlations were calculated using Spearman's correlation $\left(r_{\mathrm{s}}\right)$. Owing to its skewed distribution, fecal calprotectin was log-transformed and used as an outcome in linear regression with a stepwise model. All tests were two-tailed, and $p \leq 0.05$ was considered statistically significant.

\section{Results}

Characteristics of the study population

In total, 164 patients, comprising $45 \%$ women and $55 \%$ men, completed the study and were examined at the two study visits (baseline and 5-year follow-up). The characteristics of the study population are provided in Table 1.

\section{Intraindividual variation in fecal calprotectin between baseline and 5-year follow-up}

Fecal calprotectin was elevated $(>50 \mathrm{mg} / \mathrm{kg})$ in $70.7 \%$ (116 of 164) of the patients at baseline and in 63.4\% (104 of 164) of the patients at 5-year follow-up. The levels of fecal calprotectin did not differ between baseline and follow-up $(p=0.660)$ (Table 1).

The change in fecal calprotectin between baseline and the 5-year follow-up was $\leq 50 \mathrm{mg} / \mathrm{ml}$ in $48 \%$ of the patients, 51 $100 \mathrm{mg} / \mathrm{kg}$ in $16 \%$, and $101-200 \mathrm{mg} / \mathrm{kg}$ in $16 \%$. The median change between baseline and 5-year follow-up for calprotectin was 1.5 (IQR -52.7 to 52.7 ) $\mathrm{mg} / \mathrm{kg}$. The intraindividual 
Table 1 Characteristics of the 164 patients with ankylosing spondylitis at baseline and 5-year follow-up

\begin{tabular}{|c|c|c|c|}
\hline & Baseline & 5-Year follow-up & $p$ Value \\
\hline Sex, female/male & $74(45) / 90(55)$ & & \\
\hline Age, years & $49.5(41-62)$ & $54.5(46-67)$ & $<0.001$ \\
\hline Years since onset of AS symptoms & $22(13-34)$ & $27(18-39)$ & $<0.001$ \\
\hline Years since AS diagnosis & $12(5-23)$ & $17(10-28)$ & $<0.001$ \\
\hline HLA-B27-positive & $141(86)$ & & \\
\hline Fecal calprotectin, mg/kg & $86(45-222)$ & $82(35-190)$ & 0.660 \\
\hline \multicolumn{4}{|l|}{ Fecal calprotectin level } \\
\hline$\leq 50 \mathrm{mg} / \mathrm{kg}$ & $48(29.3)$ & $60(36.6)$ & 0.660 \\
\hline $51-199 \mathrm{mg} / \mathrm{kg}$ & $69(42.1)$ & $64(39.0)$ & \\
\hline 200-499 mg/kg & $32(19.5)$ & $29(17.7)$ & \\
\hline 500-999 mg/kg & $13(7.9)$ & $8(4.9)$ & \\
\hline$>1000 \mathrm{mg} / \mathrm{kg}$ & $2(1.2)$ & $3(1.8)$ & \\
\hline Serum calprotectin, ng/ml & $645(282-705)$ & No data & N/A \\
\hline CRP, mg/L & $2(1-6)$ & $3(1-6)$ & 0.434 \\
\hline $\mathrm{ESR}, \mathrm{mm} / \mathrm{h}$ & $11(7-18)$ & $8(4-14)$ & $<0.001$ \\
\hline ASDAS $_{\text {CRP }}$ score & $2.2(1.6-3.0)$ & $2.1(1.3-2.7)$ & $<0.001$ \\
\hline BASDAI score & $3.1(1.6-5.2)$ & $3.2(1.8-5.2)$ & 0.713 \\
\hline BAS-G score & $2.7(1.2-5.7)$ & $2.8(1.4-5.9)$ & 0.187 \\
\hline BASFI score & $2.3(1.0-3.8)$ & $2.3(1.0-4.1)$ & 0.443 \\
\hline BASMI score & $2.8(2.0-4.0)$ & $3.4(2.4-4.6)$ & $<0.001$ \\
\hline Current smoker & $15(9.1)$ & $11(6.7)$ & 0.388 \\
\hline NSAIDs & $128(78)$ & $125(76)$ & 0.868 \\
\hline Daily use & $73(45)$ & $66(40)$ & \\
\hline As needed & $55(34)$ & $59(36)$ & \\
\hline TNF blockers & $33(20)$ & $39(24)$ & 0.238 \\
\hline Infliximab & $24(15)$ & $21(13)$ & 0.664 \\
\hline Adalimumab & $4(2)$ & $8(5)$ & 0.289 \\
\hline Golimumab & $0(0)$ & $4(2)$ & N/A \\
\hline Etanercept & $5(3)$ & $6(4)$ & 1.000 \\
\hline \multicolumn{4}{|l|}{ DMARDs } \\
\hline Methotrexate & $35(21)$ & $29(18)$ & 0.189 \\
\hline Sulfasalazine & $16(10)$ & $8(5)$ & 0.004 \\
\hline \multicolumn{4}{|c|}{ Regular occurrence of gastrointestinal symptoms } \\
\hline Loose stools & $70(43)$ & $66(40)$ & 0.401 \\
\hline Mucus in diarrhea & $25(15)$ & $34(21)$ & 0.405 \\
\hline Blood in stools & $22(13)$ & $21(13)$ & 1.000 \\
\hline Blood in diarrhea & $8(5)$ & $9(5)$ & 1.000 \\
\hline Abdominal pain & $24(15)$ & $33(20)$ & 0.210 \\
\hline Obstipation & $54(33)$ & $41(25)$ & 0.008 \\
\hline Reflux symptoms & $65(40)$ & $62(38)$ & 0.391 \\
\hline Epigastric pain & $47(29)$ & $46(28)$ & 1.000 \\
\hline
\end{tabular}

Abbreviations: AS Ankylosing spondylitis, CRP C-reactive protein, DMARD Disease-modifying antirheumatic drug, ESR Erythrocyte sedimentation rate, $A S D A S_{C R P}$ Ankylosing Spondylitis Disease Activity Score based on C-reactive protein, BASDAl Bath Ankylosing Spondylitis Disease Activity Index, BAS-G Bath Ankylosing Spondylitis Patient Global Score, BASFI Bath Ankylosing Spondylitis Functional Index, BASMI Bath Ankylosing Spondylitis Metrology Index, NSAID nonsteroidal anti-inflammatory drug, TNF tumor necrosis factor

Data are presented as median and [interquartile range] or number (\%) 
correlation coefficient for fecal calprotectin at baseline and follow-up was $r_{\mathrm{S}}=0.512(p<0.001)$ (Fig. 2a).

\section{Fecal calprotectin correlates with disease activity and physical function}

At both visits, fecal calprotectin was positively and significantly correlated with parameters reflecting higher disease activity and poorer function at the same visit,

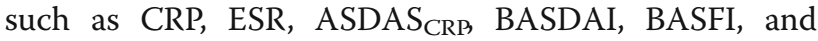
BASMI. In addition, fecal calprotectin at baseline was positively associated with higher levels of CRP, ESR, ASDAS $_{\mathrm{CRB}}$, and BASFI at 5-year follow-up (Table 2).

The patients who were smoking at baseline (9\%) had, in comparison with nonsmokers, significantly higher fecal calprotectin at 5-year follow-up (median [IQR] 107 [43-402] vs. 85 [45-221] $\mathrm{mg} / \mathrm{kg}, p=0.026)$. Baseline serum calprotectin was also positively correlated with fecal calprotectin, both at baseline $\left(\mathrm{r}_{\mathrm{S}}=0.252, p=0.001\right)$ and at 5-year follow-up $\left(r_{\mathrm{S}}=0.170, p=0.030\right)$.

\section{Fecal calprotectin and medication}

The medications used at baseline and 5-year follow-up are listed in Table 1. Fecal calprotectin was significantly higher in NSAID users than in nonusers at both study visits (baseline median [IQR] 105 [45-262] vs. 68 [44-93] mg/kg, $p=$ 0.032; 5-year follow-up 93 [44-215] vs. 40 [23-120] mg/kg, $p=0.011$ ) (Fig. 3a). The users of anti-tumor necrosis factor (anti-TNF) antibodies (infliximab, adalimumab, golimumab) had significantly lower fecal calprotectin than patients without TNF blocker therapy at both visits (baseline 43 [17-84] vs. 99 [54-256] $\mathrm{mg} / \mathrm{kg}, p=0.004$; 5-year follow-up 48 [26-135] vs. 89 [40-210] $\mathrm{mg} / \mathrm{kg}, p=0.022)$, whereas no such difference was found between users of TNF receptor fusion proteins (etanercept) and nonusers of TNF blockers. At 5-year follow-up, the patients treated with TNF receptor fusion proteins had significantly higher fecal calprotectin than the patients treated with anti-TNF antibodies (200 [93-555] vs. 48 [26-135] mg/kg; $p=0.016$ ) (Fig. 3b). Comedication with methotrexate and a TNF blocker was common. Methotrexate was mostly taken in low doses (5$15 \mathrm{mg}$ weekly). At 5-year follow-up, the use of methotrexate among patients on anti-TNF antibodies was not significantly different from the use in patients taking etanercept (18 of 33 [54.5\%] vs. 2 of 6 [33\%]; $p=0.407$ by Fisher's exact test).

Although the patients treated with TNF blockers had a significantly lower frequency of NSAID intake than the patients without TNF blockers, the significant differences in fecal calprotectin between users and nonusers of disease-modifying antirheumatic drugs and/or TNF blockers remained after adjustment for NSAID use. Linear regression analysis was performed with logtransformed fecal calprotectin at 5-year follow-up as an outcome measure, and the following baseline values were used as covariates: sex, age, serum calprotectin, fecal calprotectin, CRP, ASDAS CRB $_{\text {B }}$ BASFI, smoking, and use of NSAIDs and anti-TNF antibodies/TNF receptor fusion proteins. Only fecal calprotectin at baseline $(\beta=0.001, \mathrm{SE}$ $=0.000,95 \%$ CI $0.0008-0.0015, p<0.001)$ and smoking at
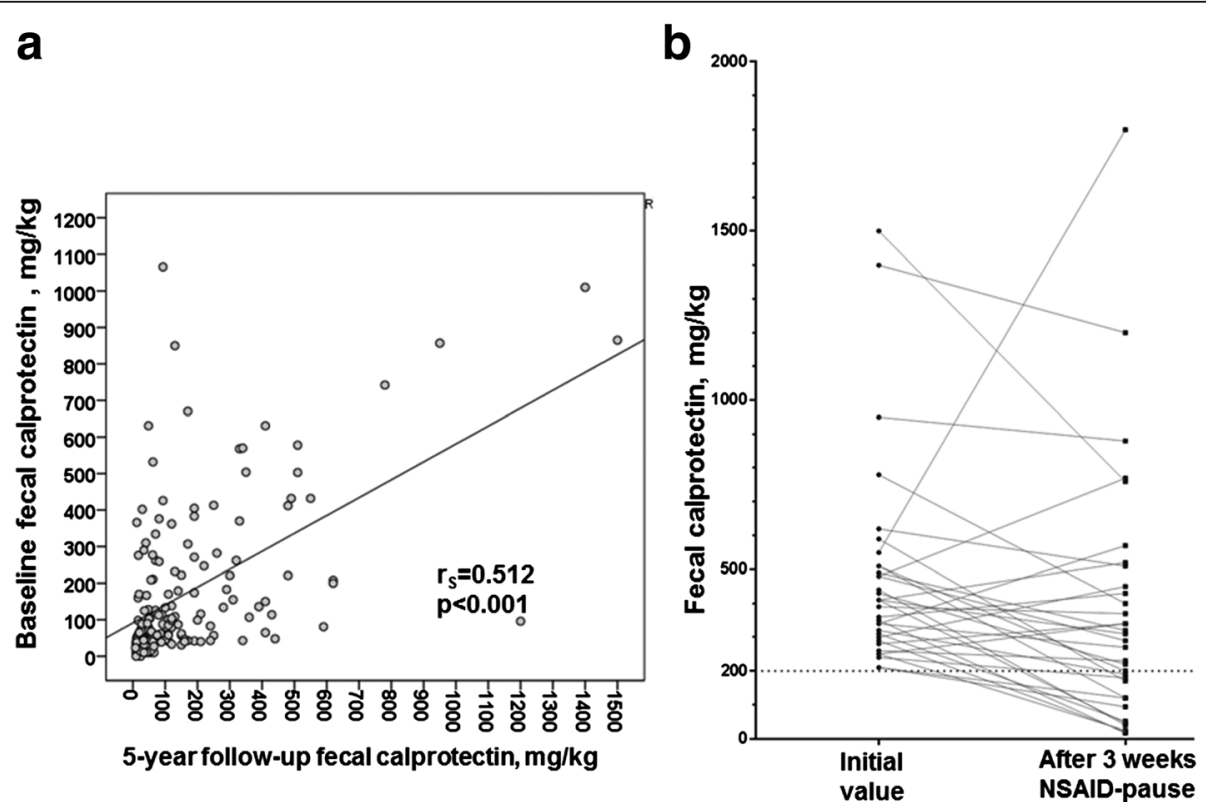

Fig. 2 a Scatterplot of fecal calprotectin at baseline and 5-year follow-up in 164 patients with ankylosing spondylitis (AS). b Fecal calprotectin before and after a 3-week pause of nonsteroidal anti-inflammatory drug (NSAID) use at 5-year follow-up in 33 patients with AS 
Table 2 Spearman's correlations between fecal calprotectin and parameters reflecting disease activity and physical function at baseline and 5-year follow-up

\begin{tabular}{|c|c|c|c|c|c|c|c|c|c|c|c|c|}
\hline & \multicolumn{2}{|l|}{ CRP } & \multicolumn{2}{|l|}{ ESR } & \multicolumn{2}{|l|}{$\mathrm{ASDAS}_{\mathrm{CRP}}$} & \multicolumn{2}{|l|}{ BASDAI } & \multicolumn{2}{|l|}{ BASFI } & \multicolumn{2}{|l|}{ BASMI } \\
\hline & Baseline & $\begin{array}{l}\text { 5-year } \\
\text { follow-up }\end{array}$ & Baseline & $\begin{array}{l}\text { 5-year } \\
\text { follow-up }\end{array}$ & Baseline & $\begin{array}{l}\text { 5-year } \\
\text { follow-up }\end{array}$ & Baseline & $\begin{array}{l}\text { 5-year } \\
\text { follow-up }\end{array}$ & Baseline & $\begin{array}{l}\text { 5-year } \\
\text { follow-up }\end{array}$ & Baseline & $\begin{array}{l}\text { 5-year } \\
\text { follow-up }\end{array}$ \\
\hline FC Baseline & 0.280 & 0.209 & 0.222 & 0.169 & 0.260 & 0.240 & 0.190 & N.S. & 0.166 & 0.166 & N.S. & N.S. \\
\hline$p$-value & $<0.001$ & $p=0.007$ & $p=0.004$ & $p=0.031$ & $p=0.001$ & $p=0.002$ & $p=0.016$ & & $p=0.034$ & $p=0.034$ & & \\
\hline FC 5-year & N.S. & 0.219 & N.S. & 0.172 & N.S. & 0.207 & N.S. & N.S. & N.S. & 0.154 & N.S. & 0.207 \\
\hline$p$-value & & $p=0.005$ & & $p=0.027$ & & $p=0.008$ & & & & $p=0.048$ & & $p=0.008$ \\
\hline
\end{tabular}

Abbreviations: CRP C-reactive protein, ESR Erythrocyte sedimentation rate, $A S D A S_{C R P}$ Ankylosing Spondylitis Disease Activity Score based on C-reactive protein, BASDAI Bath Ankylosing Spondylitis Disease Activity Index, BASFI Bath Ankylosing Spondylitis Functional Index, BASMI Bath Ankylosing Spondylitis Metrology Index, FC fecal calprotectin

baseline $(\mathrm{B}=0.241, \mathrm{SE}=0.121,95 \% \mathrm{CI} 0.002-0.479, p=$ 0.048 ) remained independently associated with higher fecal calprotectin at 5-year follow-up $\left(R^{2}=0.247\right)$.

\section{Gastrointestinal symptoms}

A high frequency of gastrointestinal symptoms (diarrhea, presence of blood or mucus in stools, obstipation, abdominal pain, tenesmus, reflux symptoms, and epigastric pain) was reported by the participants both at baseline and at 5year follow-up (Table 1). There were no significant associations between the levels of fecal calprotectin and gastrointestinal symptoms at any of the time points, however.

\section{Fecal calprotectin before and after of 3-week NSAID} pause

At 5-year follow-up, the patients who had fecal calprotectin $\geq 200 \mathrm{mg} / \mathrm{kg}(n=40[24 \%])$ were asked to send in a new stool sample after pausing NSAID use for 3 weeks, which a total of 33 patients did. After the 3-week NSAID pause, fecal calprotectin dropped by 116 ( -20 to 289 ) $\mathrm{mg} / \mathrm{kg}$ from a range of $410(295-510) \mathrm{mg} / \mathrm{kg}$ to 290 (120-480) $\mathrm{mg} / \mathrm{kg}(p=0.005)$ (Fig. 2b).

\section{Development of gut inflammation during 5 years of follow-up}

Ileocolonoscopies were performed in 8 patients at baseline and in 16 patients at 5-year follow-up (Fig. 1). The findings from the ileocolonoscopies are summarized in Table 3. Altogether, 10 (41.7\%) of the 24 patients who underwent ileocolonoscopy had inflammatory changes in the gut biopsies. In addition, five patients (20.8\%) had only macroscopic changes.

At 5-year follow-up, 3 patients (1.5\%) were diagnosed with CD (corresponding to an annual incidence of 294 new cases per 100,000 person-years), and 1 patient $(0.5 \%)$ was diagnosed with lymphocytic colitis. No cases of UC
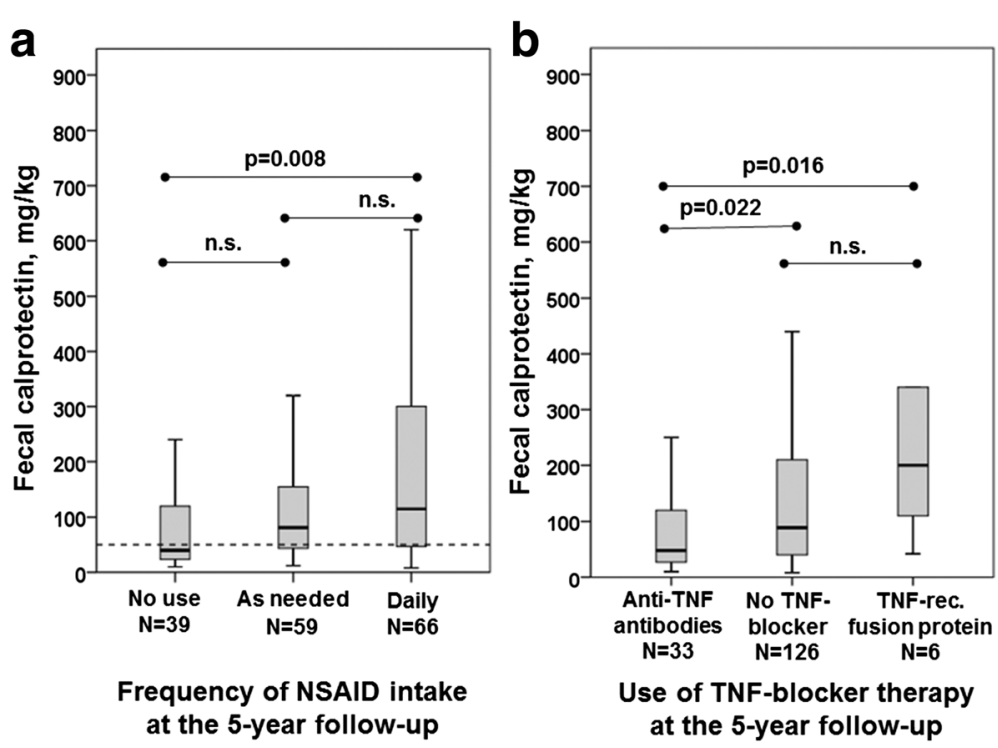

Fig. 3 a Box plot showing the association between fecal calprotectin and frequency of NSAID intake at 5-year follow-up. b Box plot showing the distribution of fecal calprotectin among patients on anti-TNF antibodies (infliximab, adalimumab, golimumab) vs. no TNF blocker therapy vs. TNF receptor fusion proteins (etanercept) at 5-year follow-up. Values are median (horizontal lines), IQR (boxes), and total range (whiskers). NSAID Nonsteroidal anti-inflammatory drug, TNF Tumor necrosis factor 
Table 3 Development of gut inflammation in 204 patients with ankylosing spondylitis between baseline and 5-year follow-up

\begin{tabular}{|c|c|c|c|}
\hline Type of inflammation & Baseline & $\begin{array}{l}\text { 5-Year } \\
\text { follow-up }\end{array}$ & Total \\
\hline Diagnosis of Crohn's disease & 1 & 2 & 3 \\
\hline Diagnosis of ulcerative colitis & 0 & 0 & 0 \\
\hline Diagnosis of lymphocytic colitis & 1 & 0 & 1 \\
\hline Subclinical findings in the distal ileum & & & 5 \\
\hline $\begin{array}{l}\text { Macroscopic changes: } \\
\text { aphthous ulcerations }\end{array}$ & & 1 & \\
\hline $\begin{array}{l}\text { Microscopic changes: } \\
\text { chronic inflammation }\end{array}$ & & 1 & \\
\hline $\begin{array}{l}\text { Both macroscopic and microscopic } \\
\text { changes }\end{array}$ & 2 & 1 & \\
\hline Subclinical findings in the colon & & & 6 \\
\hline $\begin{array}{l}\text { Macroscopic changes: } \\
\text { ulcerations }\end{array}$ & 3 & 1 & \\
\hline $\begin{array}{l}\text { Microscopic changes: } \\
\text { chronic inflammation }\end{array}$ & & 1 & \\
\hline $\begin{array}{l}\text { Both macroscopic and microscopic } \\
\text { changes }\end{array}$ & & 1 & \\
\hline Total & & & 15 \\
\hline
\end{tabular}

were found. Additionally, five patients (2.5\%) demonstrated characteristics of subclinical CD with aphthous ulcerations and/or chronic inflammation in the distal ileum, and another six patients (2.9\%) had ulcerations and/or chronic inflammation in the colon. In total, 15 patients (7.4\%) demonstrated characteristics of inflammation in the large or small intestine during the 5-year follow-up period.

\section{Predictors for development of CD}

At baseline, the patients who developed CD had, in comparison with the other patients, higher fecal calprotectin $(570$ [271-570] $\mathrm{mg} / \mathrm{kg}$ vs. 85 [43-230]; $p=0.014$ ) and more often reported having diarrhea containing mucus ( 3 of 3 vs. 30 of 201; $p=0.004$ ). No significant associations were found between the development of CD and the other baseline parameters. A receiver operating characteristic (ROC) curve was created with baseline fecal calprotectin as the test variable and development of $\mathrm{CD}$ as the categorical state variable. The area under the curve was 0.913 (95\% CI $0.805-1.000 ; p=0.014)$. Using a threshold for baseline fecal calprotectin of $266 \mathrm{mg} / \mathrm{kg}$, based on this ROC curve, the sensitivity for development of CD was $100 \%$ and the specificity was $78.7 \%$.

\section{Discussion}

In this longitudinal 5-year study of a well-characterized cohort of patients with AS, we followed the intraindividual variation in fecal calprotectin in relation to disease activity and medication, and we determined the incidence and predictors for IBD. Fecal calprotectin was elevated $(>50 \mathrm{mg} / \mathrm{kg}$ ) in approximately two-thirds of the patients at both the baseline and 5-year follow-up visits. The intraindividual variation was moderate; in $80 \%$ of the patients, fecal calprotectin changed $<200 \mathrm{mg} / \mathrm{kg}$ between the two measurement time points. Smoking and elevated fecal calprotectin at baseline were the strongest predictors for high fecal calprotectin at 5-year follow-up. Of the 204 patients included at baseline, 1.5\% were diagnosed with $\mathrm{CD}$ and $0.5 \%$ with lymphocytic colitis at 5year follow-up. High fecal calprotectin and presence of mucus in diarrhea at baseline were the main predictors of development of $\mathrm{CD}$ in this cohort.

Our results indicate that gut inflammation in AS is associated with higher disease activity in rheumatic disease. Increased fecal calprotectin at baseline was associated with higher ASDAS ${ }_{\mathrm{CRB}}$ BASDAI, BASFI, CRP, and ESR at 5-year follow-up. Early prospective studies showed a link between active gut inflammation and persistence of joint and spine inflammation as well as more chronic radiographic changes in the sacroiliac joint and spine [18, 27]. Researchers in two cross-sectional studies reported higher fecal calprotectin in AS than in healthy control subjects $[28,29]$. One of the studies showed a positive correlation between fecal calprotectin and BASDAI, BASFI, ESR, and CRP [29]. In studies with the Belgian Inflammatory Arthritis and spoNdylitis cohorT (GIANT) of early SpA, the presence of histological gut inflammation was associated with higher BASDAI and higher BASMI and was also linked to a greater degree of bone marrow edema in the sacroiliac joints visualized by magnetic resonance imaging $[13,30]$. The longitudinal results of our study support they hypothesis that inflammation in the gut and the musculoskeletal system may be linked. If gut inflammation is the cause or the consequence of locomotor disease is unknown, however, and fecal calprotectin is only a surrogate measure for gut inflammation.

In a recent report based on the GIANT cohort, fecal calprotectin, serum calprotectin, and CRP were also significantly higher in patients with microscopic gut inflammation [31]. We found that serum calprotectin at baseline was positively correlated with fecal calprotectin, both at baseline and at 5-year follow-up, but serum calprotectin was not a significant predictor for the development of CD.

In the present study, the use of anti-TNF antibodies was associated with lower fecal calprotectin, whereas use of TNF receptor fusion proteins was associated with higher levels of fecal calprotectin, at 5-year follow-up. Infliximab and adalimumab, but not etanercept, are efficacious in the treatment of CD and UC [32]. Similarly, in earlier studies, more flares and onset of IBD were observed in patients with AS treated with etanercept than in patients treated with infliximab [33, 34]. 
The 5-year incidence of $\mathrm{CD}$ in the present study was $1.5 \%$, which corresponds to an annual incidence of 294 new cases per 100,000 person-years. This can be compared with the highest reported annual incidence of $C D$ in the general population of 12.7 per 100,000 person years in Europe and 20.2 per 100,000 person-years in North America [35]. Mielants et al. reported an incidence of IBD of $5 \%$ in a cohort of 217 patients with SpA or AS during a median follow-up of 5.5 years [19]. Similarly to our study, CD was more common than UC in their study. In contrast to our study, ileocolonoscopy was performed on all patients at inclusion, and 49 patients underwent a second endoscopy. Because patients with fecal calprotectin $<200 \mathrm{mg} / \mathrm{kg}$ were not examined with endoscopy in our study, cases with IBD despite lower fecal calprotectin may have been missed. Moreover, the earlier studies were performed in the "prebiologic era," which may have affected the results. Furthermore, a few patients with persistently elevated fecal calprotectin declined ileocolonoscopy.

In our study, elevated fecal calprotectin and presence of mucus in diarrhea at baseline were the only significant predictors of the development of CD. The low number of new cases of CD $(n=3)$ may have affected the robustness of the results and the possibility of finding other significant predictors.

The high use of NSAIDs among patients with AS is a problem when studying gut inflammation. NSAIDinduced enteropathy is difficult to distinguish from ASassociated gut inflammation and is associated with increased fecal calprotectin [23]. In the present study, NSAID use was stopped for 3 weeks before retesting fecal calprotectin and before ileocolonoscopies, which resulted in a drop of a median of $116 \mathrm{mg} / \mathrm{kg}$ in fecal calprotectin. We found that 3-week cessation of NSAID use before testing fecal calprotectin was a reasonable course of action and acceptable for most patients.

The strengths of the present study are its prospective design with two measurement time points, the relatively large and well-characterized cohort, and cessation of NSAIDs before ileocolonoscopy at follow-up. The study's weaknesses are that ileocolonoscopy was not performed in all patients, which may have resulted in a lower incidence of IBD. The ileocolonoscopies were also performed at different thresholds of fecal calprotectin at baseline and 5-year follow-up (Fig. 1).

\section{Conclusions}

Fecal calprotectin was elevated in two-thirds of the patients with AS and was positively associated with parameters reflecting higher disease activity and poorer physical function at both study visits. Use of NSAIDs and TNF receptor fusions proteins was associated with higher levels of fecal calprotectin, whereas use of anti-TNF antibodies was associated with lower levels of fecal calprotectin.
Further studies are needed to prove whether anti-TNF treatment has an effect on subclinical gut inflammation in AS and whether it can prevent the development of IBD. The 5-year incidence of CD was $1.5 \%$, and elevated fecal calprotectin at baseline was the strongest predictor of the development of IBD. On the basis of these results, we propose that fecal calprotectin may be a potential biomarker to identify patients with AS at risk of developing IBD. Thus, fecal calprotectin quantification should be considered, especially in patients with high disease activity and gastrointestinal symptoms. If possible, NSAIDs should be stopped temporarily before measuring fecal calprotectin to reduce the confounding effect of NSAID enteropathy on the measurement.

\section{Abbreviations \\ AS: Ankylosing spondylitis; ASDAS: Ankylosing Spondylitis Disease Activity Score:

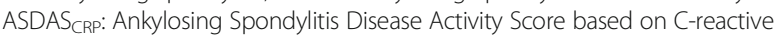 protein; BASDAl: Bath Ankylosing Spondylitis Disease Activity Index; BASFI: Bath Ankylosing Spondylitis Functional Index; BAS-G: Bath Ankylosing Spondylitis Patient Global Score; BASMI: Bath Ankylosing Spondylitis Metrology Index; CD: Crohn's disease; CRP: C-reactive protein; DMARD: Disease-modifying antirheumatic drug; ELISA: Enzyme-linked immunosorbent assay; ESR: Erythrocyte sedimentation rate; GIANT: Belgian Inflammatory Arthritis and spoNdylitis cohorT; IBD: Inflammatory bowel disease; NSAID: Nonsteroidal anti-inflammatory drug; ROC: Receiver operator characteristic; \\ SpA: Spondylarthritis; TNF: Tumor necrosis factor; UC: Ulcerative colitis}

\section{Acknowledgements}

We thank all the patients who participated in the study.

\section{Funding}

This work was supported by grants from the Health and Medical Care Executive Board of the Västra Götaland, Rune and Ulla Amlövs Foundation for Rheumatology Research, Göteborg Association against Rheumatism, the Swedish Association Against Rheumatism, the Medical Society of Göteborg, and the Region Västra Götaland (agreement concerning research and education of doctors), Controlling Chronic Inflammatory Diseases with Combined Efforts (COMBINE), the Margareta Rheuma Research Foundation, and the Swedish Society of Medicine.

\section{Availability of data and materials}

The datasets analyzed during the present study are available from the corresponding author on reasonable request.

\section{Authors' contributions}

EK participated in the design of the study, examined the patients, collected data, performed statistical analyses, and drafted the manuscript. HS participated in the design of the study, performed the ileocolonoscopies, and participated in the collection and interpretation of data. AS was responsible for the fecal analyses and interpretation of data. AD participated in the design of the study, examined the patients, and collected data. HC participated in the design of the study and the interpretation of data. LÖ participated in the design of the study and the collection and interpretation of data. HFd'E supervised the study and was responsible for study design and interpretation of data. All authors critically reviewed the manuscript, approved the final version to be published, and agreed to be accountable for all aspects of the work.

\section{Competing interests}

The authors declare that they have no financial or nonfinancial competing interests.

Consent for publication

Not applicable. 


\section{Ethics approval and consent to participate}

The study was approved by the regional ethics committee in Gothenburg and was carried out in accordance with the Helsinki declaration. All participants gave their written informed consent.

\section{Author details}

'Department of Rheumatology and Inflammation Research, Sahlgrenska Academy at the University of Gothenburg, Guldhedsgatan 10A, S-413 46 Gothenburg, Sweden. ${ }^{2}$ Department of Internal Medicine, Södra Älvsborgs Sjukhus, Borås, Sweden. ${ }^{3}$ Department of Internal Medicine and Clinical Nutrition, Sahlgrenska Academy at the University of Gothenburg, Gothenburg, Sweden. ${ }^{4}$ Department of Microbiology and Immunology, Sahlgrenska Academy at the University of Gothenburg, Gothenburg, Sweden. ${ }^{5}$ Sweden School of Health and Education, University of Skövde, Skövde, Sweden. ${ }^{6}$ Rheumatology Unit, Department of Public Health and Clinical Medicine, Umeå University, Umeå, Sweden.

Received: 31 August 2016 Accepted: 6 January 2017

Published online: 02 February 2017

\section{References}

1. Reveille JD. Genetics of spondyloarthritis-beyond the MHC. Nat Rev Rheumatol. 2012;8(5):296-304.

2. Jacques $P$, Van Praet L, Carron P, Van den Bosch F, Elewaut D. Pathophysiology and role of the gastrointestinal system in spondyloarthritides. Rheum Dis Clin North Am. 2012;38(3):569-82.

3. Thjodleifsson B, Geirsson AJ, Bjornsson S, Bjarnason I. A common genetic background for inflammatory bowel disease and ankylosing spondylitis: a genealogic study in Iceland. Arthritis Rheum. 2007;56(8):2633-9.

4. Bjarnason I, Helgason KO, Geirsson AJ, Sigthorsson G, Reynisdottir I, Gudbjartsson D, et al. Subclinical intestinal inflammation and sacroiliac changes in relatives of patients with ankylosing spondylitis. Gastroenterology. 2003;125(6):1598-605.

5. Orchard TR, Wordsworth BP, Jewell DP. Peripheral arthropathies in inflammatory bowel disease: their articular distribution and natural history. Gut. 1998;42(3):387-91.

6. Orchard TR, Holt H, Bradbury L, Hammersma J, McNally E, Jewell DP, et al. The prevalence, clinical features and association of HLA-B27 in sacroiliitis associated with established Crohn's disease. Aliment Pharmacol Ther. 2009;29(2):193-7.

7. de Vlam K, Mielants H, Cuvelier C, De Keyser F, Veys EM, De Vos M. Spondyloarthropathy is underestimated in inflammatory bowel disease: prevalence and HLA association. J Rheumatol. 2000;27(12):2860-5.

8. Baeten D, De Keyser F, Mielants H, Veys EM. Ankylosing spondylitis and bowel disease. Best Pract Res. 2002;16(4):537-49.

9. Vavricka SR, Schoepfer A, Scharl M, Lakatos PL, Navarini A, Rogler G. Extraintestinal manifestations of inflammatory bowel disease. Inflamm Bowel Dis. 2015:21(8):1982-92.

10. Lee YH, Ji JD, Kim JS, Bak YT, Lee CH, Kim CH, et al. Ileocolonoscopic and histologic studies of Korean patients with ankylosing spondylitis. Scand J Rheumatol. 1997;26(6):473-6.

11. Mielants H, Veys EM, Cuvelier C, de Vos M. Ileocolonoscopic findings in seronegative spondylarthropathies. Br J Rheumatol. 1988;27 Suppl 2:95-105.

12. Leirisalo-Repo M, Turunen U, Stenman S, Helenius P, Seppala K. High frequency of silent inflammatory bowel disease in spondylarthropathy. Arthritis Rheum. 1994;37(1):23-31

13. Van Praet $L$, Van den Bosch FE, Jacques $P$, Carron $P$, Jans $L$, Colman $R$, et al. Microscopic gut inflammation in axial spondyloarthritis: a multiparametric predictive model. Ann Rheum Dis. 2013:72(3):414-7.

14. Cuvelier C, Barbatis C, Mielants H, De Vos M, Roels H, Veys E. Histopathology of intestinal inflammation related to reactive arthritis. Gut. 1987;28(4):394-401

15. Mielants H, Veys EM, Cuvelier C, De Vos M, Goemaere S, De Clercq L, et al. The evolution of spondyloarthropathies in relation to gut histology. II. Histological aspects. J Rheumatol. 1995;22(12):2273-8.

16. Van Praet $L$, Jacques $P$, Van den Bosch $F$, Elewaut $D$. The transition of acute to chronic bowel inflammation in spondyloarthritis. Nat Rev Rheumatol. 2012;8(5):288-95.

17. Stolwijk C, van Tubergen A, Castillo-Ortiz JD, Boonen A. Prevalence of extra-articular manifestations in patients with ankylosing spondylitis: a systematic review and meta-analysis. Ann Rheum Dis. 2015;74(1):65-73.
18. De Vos M, Mielants H, Cuvelier C, Elewaut A, Veys E. Long-term evolution of gut inflammation in patients with spondyloarthropathy. Gastroenterology. 1996;110(6):1696-703.

19. Mielants H, Veys EM, De Vos M, Cuvelier C, Goemaere S, De Clerca L, et al. The evolution of spondyloarthropathies in relation to gut histology. I. Clinical aspects. J Rheumatol. 1995:22(12):2266-72.

20. Tibble J, Teahon K, Thjodleifsson B, Roseth A, Sigthorsson G, Bridger S, et al. A simple method for assessing intestinal inflammation in Crohn's disease. Gut. 2000;47(4):506-13.

21. Foell $\mathrm{D}$, Wittkowski $H$, Roth J. Monitoring disease activity by stool analyses: from occult blood to molecular markers of intestinal inflammation and damage. Gut. 2009;58(6):859-68.

22. Gisbert JP, McNicholl AG. Questions and answers on the role of faecal calprotectin as a biological marker in inflammatory bowel disease. Dig Liver Dis. 2009:41(1):56-66.

23. Higuchi K, Umegaki E, Watanabe T, Yoda Y, Morita E, Murano M, et al. Present status and strategy of NSAIDs-induced small bowel injury. $J$ Gastroenterol. 2009;44(9):879-88.

24. Klingberg E, Carlsten H, Hilme E, Hedberg M, Forsblad-d'Elia H. Calprotectin in ankylosing spondylitis - frequently elevated in feces, but normal in serum. Scand J Gastroenterol. 2012;47(4):435-44

25. van der Linden S, Valkenburg HA, Cats A. Evaluation of diagnostic criteria for ankylosing spondylitis: a proposal for modification of the New York criteria. Arthritis Rheum. 1984;27(4):361-8.

26. Sieper J, Rudwaleit M, Baraliakos X, Brandt J, Braun J, Burgos-Vargas R, et al. The Assessment of SpondyloArthritis international Society (ASAS) handbook: a guide to assess spondyloarthritis. Ann Rheum Dis. 2009;68 Suppl 2:ii1-44.

27. Mielants H, Veys EM, Cuvelier C, De Vos M, Goemaere S, De Clercq L, et al. The evolution of spondyloarthropathies in relation to gut histology. III. Relation between gut and joint. J Rheumatol. 1995;22(12):2279-84.

28. Matzkies FG, Targan SR, Berel D, Landers CJ, Reveille JD, McGovern DP, et al. Markers of intestinal inflammation in patients with ankylosing spondylitis: a pilot study. Arthritis Res Ther. 2012;14(6):R261.

29. Duran A, Kobak S, Sen N, Aktakka S, Atabay T, Orman M. Fecal calprotectin is associated with disease activity in patients with ankylosing spondylitis. Bosn J Basic Med Sci. 2016;16(1):71-4

30. Van Praet $L$, Jans L, Carron P, Jacques P, Glorieus E, Colman R, et al. Degree of bone marrow oedema in sacroiliac joints of patients with axial spondyloarthritis is linked to gut inflammation and male sex: results from the GIANT cohort. Ann Rheum Dis. 2014;73(6):1186-9.

31. Cypers H, Varkas G, Beeckman S, Debusschere K, Vogl T, Roth J, et al. Elevated calprotectin levels reveal bowel inflammation in spondyloarthritis. Ann Rheum Dis. 2016;75(7):1357-62.

32. Sandborn WJ, Hanauer SB, Katz S, Safdi M, Wolf DG, Baerg RD, et al. Etanercept for active Crohn's disease: a randomized, double-blind, placebocontrolled trial. Gastroenterology. 2001;121(5):1088-94.

33. Braun J, Baraliakos X, Listing J, Davis J, van der Heijde D, Haibel H, et al. Differences in the incidence of flares or new onset of inflammatory bowel diseases in patients with ankylosing spondylitis exposed to therapy with anti-tumor necrosis factor alpha agents. Arthritis Rheum. 2007:57(4):639-47.

34. Toussirot E, Houvenagel E, Goeb V, Fouache D, Martin A, Le Dantec P, et al. Development of inflammatory bowel disease during anti-TNF-alpha therapy for inflammatory rheumatic disease: a nationwide series. Joint Bone Spine. 2012:79(5):457-63.

35. Ye Y, Pang Z, Chen W, Ju S, Zhou C. The epidemiology and risk factors of inflammatory bowel disease. Int J Clin Exp Med. 2015:8(12):22529-42. 